\title{
CARACTERÍSTICAS QUÍMICAS DO SOLO EM DIFERENTES DISTÂNCIAS DO TRONCO DE EUCALIPTO E EM DIFERENTES PROFUNDIDADES ${ }^{1}$
}

\author{
Geraldo Erli de Faria ${ }^{2}$, Nairam Félix de Barros ${ }^{3}$, Roberto Ferreira de Novais ${ }^{3}$ e Ivo Ribeiro da Silva ${ }^{3}$
}

RESUMO - O conhecimento das variações espaciais verificadas em plantações de eucalipto é importante para o estabelecimento de critérios de amostragem de solo e recomendação de fertilizantes. Este trabalho, desenvolvido na região litorânea do Espírito Santo, teve por objetivo determinar a variação de características químicas do solo em diferentes distâncias do tronco de eucalipto de povoamentos com 31, 54 e 84 meses de idade. Amostras de solo foram coletadas ao redor do tronco da árvore de DAP (diâmetro a 1,30 m de altura) médio e nas distâncias de 30,60, 90,120 e $150 \mathrm{~cm}$, na direção da linha de plantio e da entrelinha, nas camadas de 0-10, 10-20 e 20-40 cm de profundidade, em cada parcela, num total de seis por povoamento. Nessas amostras foram analisados: $\mathrm{pH}$ em água (1:2,5), P e K disponíveis (Mehlich-1), Al, Ca e Mg trocáveis ( $\left.\mathrm{KCl} 1 \mathrm{~mol} \mathrm{~L}^{-1}\right)$. Os resultados indicaram variações nas características químicas do solo com a distância do tronco de eucalipto. Os teores de $\mathrm{P}, \mathrm{K}, \mathrm{Ca}^{2+} \mathrm{e} \mathrm{Al}^{3+}$ diminuíram com a distância desse tronco nas três idades avaliadas, e os valores de $\mathrm{pH}$ aumentam com a distância do eucalipto aos 31 e 84 meses, assim como os teores de $\mathrm{Mg}^{2+}$ em relação ao eucalipto com 31 meses, na direção da linha e da entrelinha. As características químicas do solo obtidas na linha e entrelinha do eucalipto aos 84 meses foram mais semelhantes, exceto $\mathrm{Ca}^{2+}$. Maiores valores de $\mathrm{pH}, \mathrm{P}, \mathrm{K}, \mathrm{Ca}^{2+}$ e $\mathrm{Mg}^{2+}$ ocorreram na camada superficial.

Palavras-chave: Nutrientes, amostragem de solo e eucalipto.

\section{CHEMICAL CHARACTERISTICS OF SOIL AT DIFFERENT DISTANCES FROM THE EUCALYPTUS TRUNK AND AT DIFFERENT DEPTHS}

\begin{abstract}
The knowledge of spatial variations in fields with eucalyptus plantations is important for the establishment of criteria of soil sampling and fertilizer recommendation. The objective of this study was to determine the soil chemical variations affected by the distance from eucalyptus trunks along and between the planting rows in eucalypt plantations at different ages (31,54, and 84 months), in the Eastern Coastal Region of Brazil. Soil samples were collected around trees whose diameter at breast height corresponded to the average of the population, and at distances of 30,60,90,120, and $150 \mathrm{~cm}$ from the trunk along and between planting rows. The samples were collected at the depths of 0-10, 10-20, and 20-40 cm and analyzed for $\mathrm{pH}$ in water (1:2,5), $\mathrm{P}$ and $\mathrm{K}$ (Mehlich-1), Ca, Mg, and $\mathrm{Al}\left(\mathrm{KCl} 1 \mathrm{~mol} \mathrm{~L}^{-1}\right)$. Results indicated variations of soil chemical properties according to the distances of trunks of eucalyptus. The concentrations of $P, \mathrm{~K}, \mathrm{Ca}^{2+}$ and $\mathrm{Al}^{3+}$ decreased with the distance of the trunk of the eucalyptus in the three evaluated ages and the values of $\mathrm{pH}$ increased with the distance of the eucalyptus with 31 and 84 months, as well as the concentrations of $\mathrm{Mg}^{2+}$ for the eucalyptus with 31 months sampled in line and interlines. The chemical attributes of the soil obtained in the line and interline directions with 84 months were similar, except for $\mathrm{Ca}^{2+}$. Higher values of $\mathrm{pH}, \mathrm{P}, \mathrm{K}, \mathrm{Ca}^{2+}$ and $\mathrm{Mg}^{2+}$ were found at the superficial layer of the soil.
\end{abstract}

Keywords: Nutrients, soil sampling and eucalyptus.

\footnotetext{
${ }^{1}$ Recebido em 26-10-2007 e aceito para publicação em 23.06.2009.

${ }^{2}$ In memoriam.

${ }_{3}^{3}$ Departamento de Solos da UFV, Viçosa, MG. E-mail: <nfbarros@ufv.br>, <rfnovais@ufv.br>e<ivosilva@ufv.br>.
} 


\section{INTRODUÇÃO}

Um solo, por mais uniforme que possa parecer, por sua topografia, cor e vegetação, apresenta variabilidade em suas características químicas, físicas e biológicas, seja em profundidade (variabilidade vertical), seja em superfície (variabilidade horizontal). Essa variabilidade pode ser aumentada pelas ações antrópicas, especialmente pelo manejo da fertilidade do solo, envolvendo a aplicação de fertilizantes e corretivos na linha de plantio, na subsuperfície do solo, ou a lanço, na superfície (SCHLINDWEIN e ANGHINONI, 2000). Aliado a isso, efeitos residuais de adubações anteriores podem aumentar, segundo Silva et al. (2003), a variabilidade espacial, como também a deposição superficial dos resíduos florestais, preferencialmente na entrelinha de povoamentos de eucalipto, em detrimento da linha de plantio, pode alterar a taxa de decomposição da matéria orgânica e a liberação dos nutrientes no solo (MIRANDA et al., 1998).

Para que a amostragem de solo seja representativa e confiável, existem métodos de amostragem de solo que consideram o ponto de coleta somente na entrelinha da cultura, conforme Raij et al. (1996), e outros, que recomendaram a coleta de amostras de solo, parte na entrelinha e parte na linha da cultura (MALAVOLTA, 1992; PRADO et al., 2001). Além disso, as amostras de solo podem, também, ser obtidas na projeção da copa de culturas perenes em sistemas agroflorestais (SALGADO et al., 2006) e a diferentes distâncias do tronco de coníferas (PALLANTeRIHA, 1990;AMIOTTIetal., 2000). Entretanto, ainda são requeridos estudos mais aprofundados e detalhados para definir as técnicas de amostragem de solo sob povoamentos florestais, haja vista a significativa variabilidade dos solos quanto aos atributos químicos (CAMBARDELLA et al., 1994).

A obtenção de amostras representativas depende de técnicas de amostragem capazes de contornar a heterogeneidade do solo, que se manifesta inclusive em curtas distâncias (SOUZA et al., 1998). Fato esse que tem sido verificado em diferentes espécies florestais nos Estados Unidos, Austrália e Argentina, a exemplo alteração de algumas características químicas do solo na área de influência direta do tronco em relação àquelas mais distantes (RYAN e McGARITY, 1983; RIHA et al., 1986; AMIOTTI et al., 2000).

Contudo, são escassos estudos relatados na literatura a respeito de métodos de amostragem de solo sob povoamentos de eucalipto que contemplem a variação espacial horizontal nas características químicas do solo, se essa variação for afetada pela posição de direção da linha de plantio ou da entrelinha e, ainda, se a idade das árvores poderia estar influenciando a formação desses gradientes (variabilidade horizontal).

Nesse contexto, este trabalho teve como objetivo determinar a variação nas características químicas do solo a diferentes distâncias horizontais do tronco de eucalipto de diferentes idades, em direção da linha de plantio e da entrelinha e a diferentes profundidades.

\section{MATERIAL E MÉTODOS}

Este estudo foi desenvolvido em plantios de eucalipto situados no Município de Aracruz, região litorânea do Estado do Espírito Santo (1948' S e 40¹7' W), com altitude média de $50 \mathrm{~m}$. O clima da região, segundo a classificação de Köppen, é do tipo Aw; tropical úmido, com estação chuvosa no verão e seca no inverno e temperatura média anual de $23^{\circ} \mathrm{C}$.

Este trabalho contemplou o híbrido clonal de Eucalyptus grandis $\mathrm{x}$ Eucalyptus urophylla ("urograndis"), material genético '1205'. Os plantios foram estabelecidos no espaçamento de $3 \times 3 \mathrm{~m}$, em solo classificado como Argissolo Amarelo distrófico (EMBRAPA, 1999), derivado do Grupo Barreiras. Foram selecionados povoamentos com 31, 54 e 84 meses de idade. Os povoamentos de 31 e de 84 meses foram estabelecidos, respectivamente, ao sul e ao norte do povoamento de 54 meses e a uma distância deste de aproximadamente $5 \mathrm{~km}$.

Antes do plantio, as três áreas onde se instalou o experimento foram submetidas entre três e cinco rotações. A rotação de avaliação foi estabelecida na entrelinha da rotação do eucalipto anterior. Previamente ao plantio das mudas (reforma), realizou-se a subsolagem, nas entrelinhas, a $40 \mathrm{~cm}$ de profundidade, seguida da aplicação de $400 \mathrm{~kg} \mathrm{ha}^{-1}$ de fosfato natural reativo de Arad sob os povoamentos de eucalipto, que foram, posteriormente, avaliados aos 31 e 54 meses, sendo neste realizada a incorporação do fosfato natural com grade leve, a $20 \mathrm{~cm}$ de profundidade, decorridos 90 dias da aplicação desse insumo. Além disso, aos cinco dias após o plantio fez-se a aplicação em coveta lateral de $100 \mathrm{~g}$ de NPK 06-30-06 mais 1\% de boro por planta. Passados 90 dias após o plantio, foram aplicados na projeção da copa, como adubação de cobertura, $100 \mathrm{~g}$ por planta de NPK 10-00-30. Esses 
povoamentos, aos 10 e 14 meses pós-plantio, receberam, respectivamente, aplicação, a lanço e em área total de $400 \mathrm{~kg} \mathrm{ha}^{-1}$ de NPK 10-00-30 e 3,0 t ha-1 de cinza de biomassa florestal e $200 \mathrm{~kg} \mathrm{ha}^{-1}$ de NPK 20-05-20 e 2,0 t ha ${ }^{-1}$ de cinza de biomassa florestal, como adubação de manutenção. No povoamento de eucalipto avaliado com 84 meses, fez-se apenas a abertura de covas manualmente, às quais foram adicionados $56 \mathrm{~g} \mathrm{de}$ superfosfato triplo por mudas. Nos talhões assim estabelecidos, foram feitas avaliações em seis parcelas de $900 \mathrm{~m}^{2}$, contendo 100 árvores cada. A seleção das árvores baseou-se na medição do diâmetro a 1,30 m de altura (DAP) das 64 árvores centrais, para definir o seu DAP médio. Selecionaram-se seis árvores que apresentavam o DAP médio, a partir das quais foi realizada a coleta de amostras de solo a diferentes distâncias do tronco e a diferentes profundidades.

Amostras de solo, nas linhas e entrelinhas de plantio, foram coletadas a 30, 60, 90, 120 e $150 \mathrm{~cm}$ de distância do tronco da árvore com DAP médio, em cada parcela, nas profundidades de 0-10, 10-20 e 20-40 cm. Foram coletadas seis amostras simples na direção da entrelinha, sendo três de cada lado da árvore média, e na direção da linha de plantio foram obtidas quatro amostras simples (duas de cada lado da árvore média), as quais foram reunidas, separadamente, para formar uma amostra composta para cada posição de amostragem. As amostras de solo foram obtidas com trado tipo caneca $(5,0 \mathrm{~cm}$ de diâmetro por $40 \mathrm{~cm}$ de altura), em época chuvosa. Além disso, coletaram-se amostras do solo que se encontrava em contato com o tronco do eucalipto, somente nas camadas de 0-10 e 10-20 cm. O procedimento de coleta das amostras de solo foi realizado em seis repetições (árvores com diâmetro médio) para cada idade do povoamento.

As amostras de solo foram secas ao ar, peneiradas (peneira de malha de 2,0 $\mathrm{mm}$ ), homogeneizadas e caracterizadas física e quimicamente, conforme Embrapa (1997). Determinaram-se: pH em água (relação solo:solução 1:2,5); P e K disponíveis, extraídos com Mehlich-1; $\mathrm{Ca}^{2+}, \mathrm{Mg}^{2+}$ e $\mathrm{Al}^{3+}$ trocáveis, extraídos com $\mathrm{KCl} 1 \mathrm{~mol} \mathrm{~L}^{-1}$. A análise textural das amostras de solo encontra-se na Tabela 1.

Os dados obtidos da análise química das amostras de solo coletadas a diferentes distâncias horizontais do eucalipto, na direção da entrelinha e da linha de plantio, foram submetidos à análise de variância, admitindo-se o delineamento inteiramente casualizado. As fontes de variação foram a distância de coleta das amostras de solo em relação ao eucalipto e a profundidade de amostragem.

Foram ajustadas equações de regressão para as distâncias horizontais de coleta das amostras de solo, na direção da linha de plantio e da entrelinha, em cada profundidade de amostragem, com o objetivo de descrever a distribuição das características químicas do solo em diferentes idades do povoamento de eucalipto. Foram selecionados modelos com base na significância dos coeficientes e no valor do $\mathrm{R}^{2}$.

Tabela 1-Análise textural de amostras de solo das camadas de 0-10, 10-20 e 20-40 cm de profundidade de povoamentos de eucalipto com 31,54 e 84 meses de idade.

Table 1 - Textural Analysis of soil samples of the layers with 0-10, 10-20 and 20-40 cm of depth from eucalyptus settlements at 31,54 and 84 months of age.

\begin{tabular}{|c|c|c|c|c|c|}
\hline \multirow{3}{*}{$\begin{array}{l}\text { Profundidade } \\
\mathrm{cm} \\
\end{array}$} & \multicolumn{2}{|c|}{ Areia } & \multirow[b]{2}{*}{ Silte } & \multirow[b]{2}{*}{ Argila } & \multirow[t]{3}{*}{ Classe Textural } \\
\hline & Grossa & Fina & & & \\
\hline & \multicolumn{4}{|c|}{$\%$} & \\
\hline \multicolumn{6}{|c|}{31 meses de idade } \\
\hline $0-10$ & 55,0 & 14,0 & 6,0 & 25,0 & Franco-Argilo-Arenosa \\
\hline $10-20$ & 50,0 & 15,0 & 7,0 & 28,0 & Franco-Argilo-Arenosa \\
\hline $20-40$ & 47,0 & 16,0 & 5,0 & 32,0 & Argilo-Arenosa \\
\hline \multicolumn{6}{|c|}{54 meses de idade } \\
\hline $0-10$ & 68,0 & 14,0 & 4,0 & 14,0 & Franco-Arenosa \\
\hline $10-20$ & 62,0 & 16,0 & 5,0 & 18,0 & Franco-Arenosa \\
\hline $20-40$ & 58,0 & 15,0 & 4,0 & 24,0 & Franco-Argilo-Arenosa \\
\hline \multicolumn{6}{|c|}{84 meses de idade } \\
\hline $0-10$ & 53,0 & 18,0 & 6,0 & 23,0 & Franco-Argilo-Arenosa \\
\hline $10-20$ & 51,0 & 19,0 & 6,0 & 24,0 & Franco-Argilo-Arenosa \\
\hline $20-40$ & 49,0 & 19,0 & 5,0 & 27,0 & Franco-Argilo-Arenosa \\
\hline
\end{tabular}




\section{RESULTADOS}

Os valores de $\mathrm{pH}$ do solo sob o povoamento de eucalipto aos 31 meses aumentaram significativamente com a distância do tronco das árvores na direção da entrelinha, nas camadas de $0-10$ e $20-40 \mathrm{~cm}$ e naquela de 10-20 cm na direção da linha de plantio e da entrelinha (Figura 1). Sob o povoamento de eucalipto aos 54 meses, verificou-se que os valores de $\mathrm{pH}$ decresceram significativamente com a distância do tronco na direção da linha de plantio e da entrelinha, na camada de $0-10 \mathrm{~cm}$ e, na linha de plantio, na profundidade de $10-20 \mathrm{~cm}$, enquanto que naquela de $20-40 \mathrm{~cm}$ se observou efeito contrário, ou seja, os valores de $\mathrm{pH}$ aumentaram com a distância do eucalipto na direção da entrelinha (Figura 2). Em relação ao povoamento de eucalipto aos 84 meses, os valores de $\mathrm{pH}$ do solo elevaram-se significativamente com a distância do tronco na direção da linha de plantio e da entrelinha, nas três profundidades amostradas (Figura 3).

Considerando apenas os efeitos significativos dos teores de $\mathrm{P}, \mathrm{Ke} \mathrm{Al}^{3+}$, verificou-se que estes diminuíram com a distância do tronco do eucalipto aos 31, 54 e 84 meses de idade, na direção da linha de plantio e da entrelinha (Figuras 1, 2 e 3). Essa tendência também foi verificada nos teores de $\mathrm{Ca}^{2+}$ sob o povoamento de eucalipto aos 54 meses (Figura 2) e naquele aos 31 meses, à exceção da camada de $10-20 \mathrm{~cm}$, na direção da entrelinha desse povoamento (Figura 1) e naquele aos 84 meses de idade na camada de $0-10 \mathrm{~cm}$ na direção da linha de plantio (Figura 3), que apresentaram efeito contrário, ou seja, os teores desse elemento aumentaram com a distância do eucalipto. No entanto, os teores de $\mathrm{Mg}^{2+}$ aumentaram com a distância do eucalipto aos 31 meses de idade na direção da linha de plantio e da entrelinha (Figura 1). Esse comportamento também foi constatado sob o povoamento de eucalipto aos 54 meses, na camada de $20-40 \mathrm{~cm}$ na direção da entrelinha, como também sob o povoamento de eucalipto aos 84 meses nas duas direções de amostragem (Figuras 2 e 3 ). Considerando as demais camadas e posições de amostragem do solo sob os povoamentos de eucalipto aos 31, 54 e 84 meses, os teores de $\mathrm{Mg}^{2+}$ diminuíram significativamente com a distância do tronco do eucalipto.

Considerando as posições de amostragem do solo, na entrelinha foram observados maiores valores de $\mathrm{pH}$ nas camadas de 0-10 e 20-40 cm, de P nas três camadas de solo amostradas, de K nas camadas de 10-20 e
20-40 $\mathrm{cm}$ e de $\mathrm{Ca}^{2+}$ na camada de $20-40 \mathrm{~cm}$ de profundidade sob o povoamento de eucalipto aos 31 meses. Na direção da linha desse povoamento, ocorreram maiores teores de $\mathrm{Ke} \mathrm{Ca}^{2+}$ na camada de $0-10 \mathrm{~cm}$, de $\mathrm{Mg}^{2+}$ nas camadas de $0-10$ e $10-20 \mathrm{~cm}^{2}$ de $\mathrm{Al}^{3+}$ na camada de $20-40 \mathrm{~cm}$ (Figura 1).

Sob o povoamento de eucalipto aos 54 meses na direção da linha, ocorreram maiores valores de $\mathrm{pH}$ e de $\mathrm{Ca}^{2+}$ na camada de $0-10 \mathrm{~cm}$ e de $\mathrm{Al}^{3+}$ na camada de 20-40 cm. Na direção da entrelinha, foram registrados maiores valores de $\mathrm{pH}$ na camada de $20-40 \mathrm{~cm}$, de $\mathrm{P}$ nas camadas de $10-20$ e 20-40 cm e de $\mathrm{K}, \mathrm{Ca}^{2+} \mathrm{e} \mathrm{Mg}^{2+}$ nas camadas de 10-20 e 20-40 cm e (Figura 2).

Na direção da linha do povoamento de eucalipto aos 84 meses, foram registrados maiores teores de $\mathrm{Ca}^{2+}$ na camada de $10-20 \mathrm{~cm}$ e de $\mathrm{Mg}^{2+}$ na camada de 10-20 e 20-40 cm. Na direção da entrelinha desse povoamento, foram registrados maiores teores de $\mathrm{P}$ e K nas três camadas de solo amostradas e de $\mathrm{Ca}^{2+}$ na camada de $20-40 \mathrm{~cm}$ de profundidade (Figura 3 ).

Os maiores teores de $\mathrm{P}$ tanto na direção da linha de plantio como na entrelinha sob o povoamento de eucalipto aos 54 meses, nas três camadas de amostragem do solo (Figura 2), podem ser decorrentes da aplicação de fosfato natural reativo na linha de plantio e a sua posterior incorporação ao solo, o que contribui para a sua solubilização (NOVAIS e SMYTH, 1999), bem como de um possível efeito residual do fosfato parcialmente acidulado aplicado na linha da rotação anterior, que corresponde à entrelinha desse povoamento.

Considerando a profundidade de coleta das amostras de solo, verificou-se que os valores de $\mathrm{pH}$ foram maiores na camada de $0-10 \mathrm{~cm}$ sob os povoamentos de eucalipto aos 31, 54 e 84 meses (Figuras 1, 2 e 3). Contudo, cabe ressaltar que na camada de $20-40 \mathrm{~cm}$, na direção da entrelinha, maiores valores de $\mathrm{pH}$ foram registrados sob o povoamento de eucalipto aos 54 meses (Figura 2). Quanto aos demais elementos, verificaram-se maiores teores de $\mathrm{P}$ na camada de $0-10$ $\mathrm{cm}$, na linha de plantio, e nas camadas de 20-40 e 10-20 $\mathrm{cm}$, na entrelinha, respectivamente, sob os povoamentos de eucalipto aos 31 e 54 meses (Figuras 1 e 2). Sob o povoamento de eucalipto aos 84 meses, maiores teores de $\mathrm{P}$ foram observados na camada de $0-10 \mathrm{~cm}$, nas duas direções de amostragem (Figura 3). Na camada superficial de amostragem do solo, foram observados maiores teores

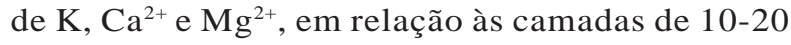


$0-10 \mathrm{~cm}$
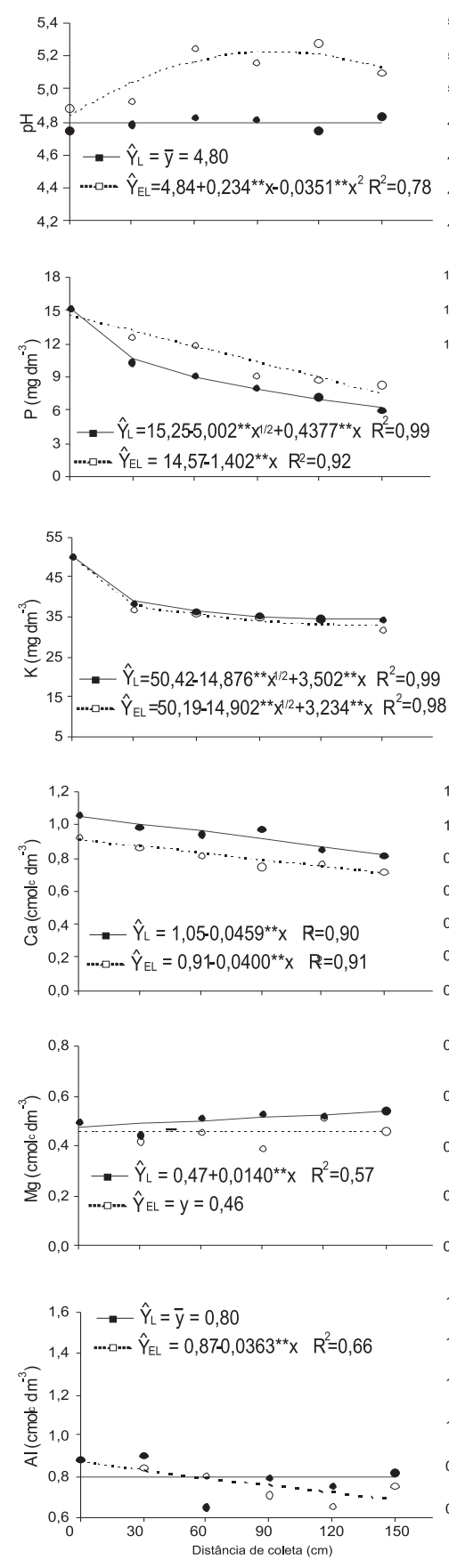

- - linha (L)
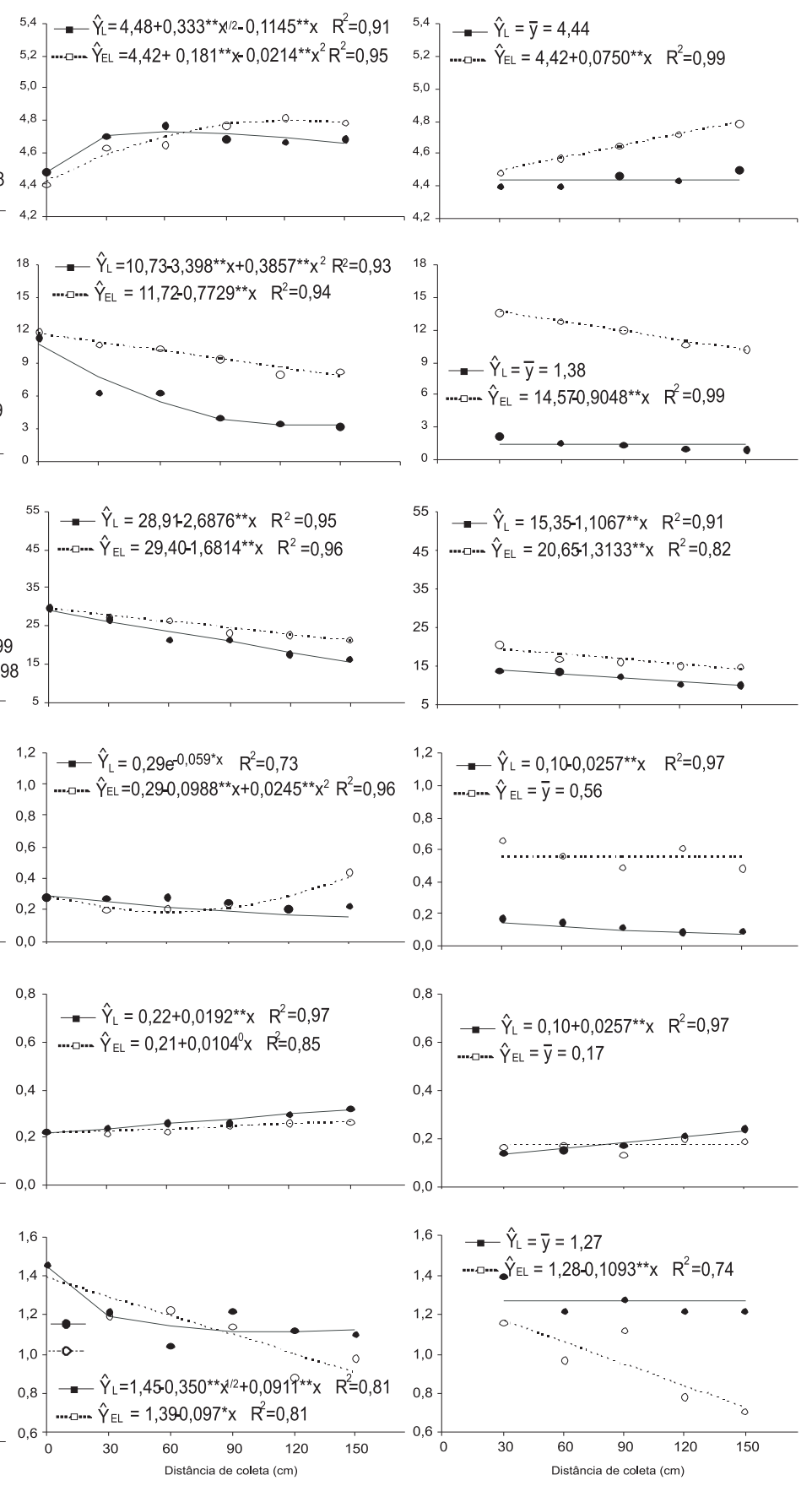

Figura 1 - Valores médios de $\mathrm{pH}, \mathrm{P}, \mathrm{K}, \mathrm{Ca}^{2+}, \mathrm{Mg}^{2+} \mathrm{e} \mathrm{Al}^{3+}$ a diferentes distâncias do eucalipto com 31 meses nas camadas de 0-10, 10-20 e 20-40 cm, na direção da linha e entrelinha.

Figure 1 - Medium values of $\mathrm{pH}, \mathrm{P}, \mathrm{K}, \mathrm{Ca}^{2+}, \mathrm{Mg}^{2+}$ and $\mathrm{Al}^{3+}$ at different distances of the eucalyptus with 31 months in the layers of 0-10, 10-20 and 20-40 cm, in the direction of the line and interlines. 

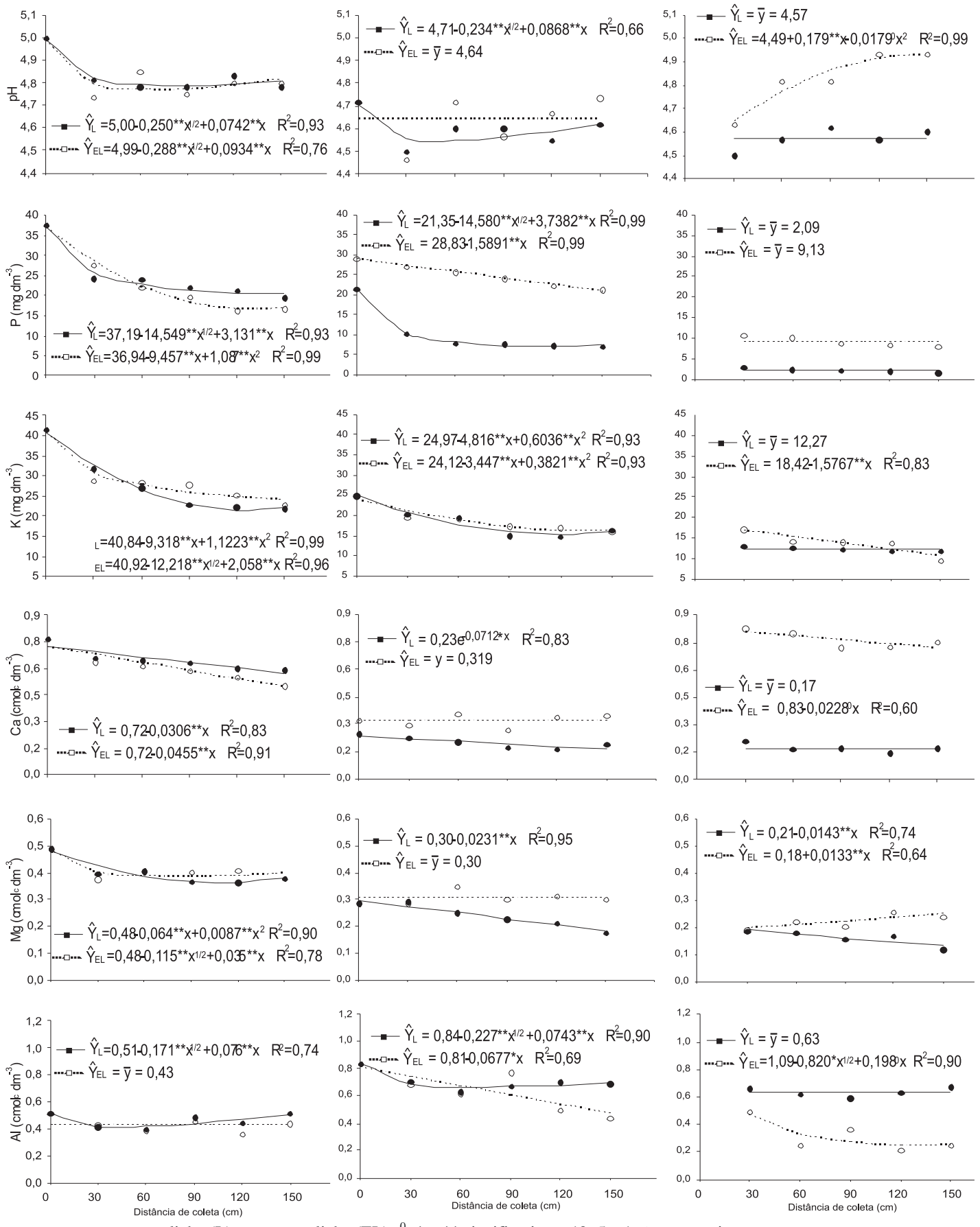

Figura 2 - Valores médios de $\mathrm{pH}, \mathrm{P}, \mathrm{K}, \mathrm{Ca}^{2+}, \mathrm{Mg}^{2+} \mathrm{e} \mathrm{Al}^{3+}$ a diferentes distâncias do eucalipto com 54 meses nas camadas de 0-10, 10-20 e 20-40 cm, na direção da linha e entrelinha.

Figure 2 - Medium values of $\mathrm{pH}, \mathrm{P}, \mathrm{K}, \mathrm{Ca}^{2+}, \mathrm{Mg}^{2+}$ and $\mathrm{Al}^{3+}$ at different distances of the eucalyptus with 54 months in the layers of 0-10,10-20 and 20-40 cm, in the direction of the line and interlines.

R. Árvore, Viçosa-MG, v.33, n.5, p.799-810, 2009 

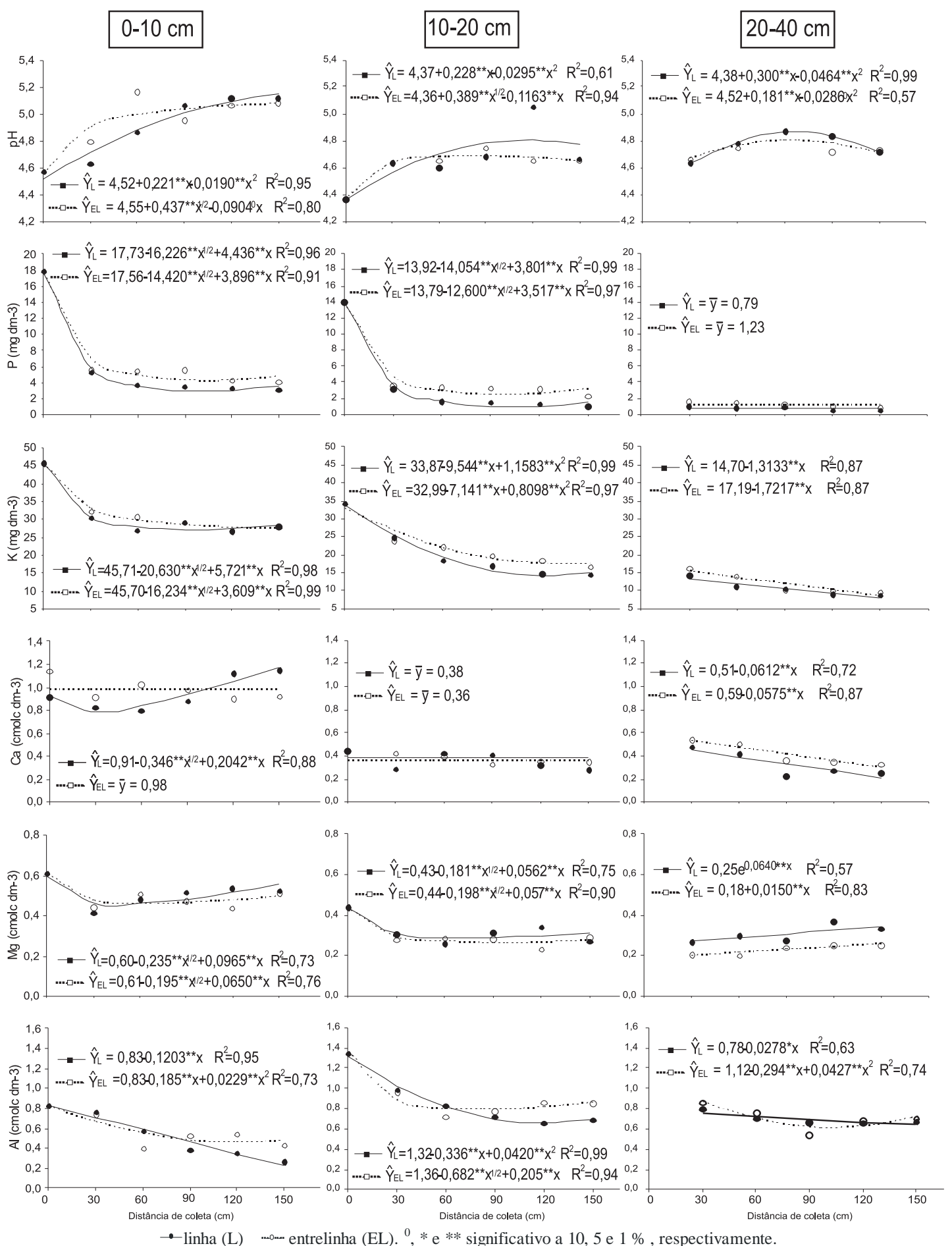

Figura 3 - Valores médios de $\mathrm{pH}, \mathrm{P}, \mathrm{K}, \mathrm{Ca}^{2+}, \mathrm{Mg}^{2+} \mathrm{e} \mathrm{Al}^{3+}$ a diferentes distâncias do eucalipto com 84 meses nas camadas de 0-10, 10-20 e 20-40 cm, na direção da linha e entrelinha.

Figure 3 - Medium values of $\mathrm{pH}, \mathrm{P}, \mathrm{K}, \mathrm{Ca}^{2+}, \mathrm{Mg}^{2+}$ and $\mathrm{Al}^{3+}$ at different distances of the eucalyptus with 84 months in the layers of $0-10,10-20$ and $20-40 \mathrm{~cm}$, in the direction of the line and interlines. 
e $20-40 \mathrm{~cm}$ sob os povoamentos de eucalipto nas três idades avaliadas (Figuras 1, 2 e 3). Contudo, cabe ressaltar que o teor de $\mathrm{Ca}^{2+}$ obtido na camada de $20-40 \mathrm{~cm}$, na entrelinha, sob o povoamento de eucalipto aos 54 meses, foi $31,03 \%$ superior àquele obtido na camada de $0-10$ $\mathrm{cm}$ (Figura 2). $\mathrm{O} \mathrm{Al}^{3+}$, por sua vez, apresentou menores teores na camada de $0-10 \mathrm{~cm}$, tanto na direção da linha quanto na entrelinha dos povoamentos de eucalipto aos 31, 54 e 84 meses (Figuras 1, 2 e 3).

\section{DISCUSSÃO}

Menores valores de $\mathrm{pH}$ mais próximos do tronco das árvores do que a maiores distâncias têm sido relatados em outras espécies (RYAN e McGARITY, 1983; RIHA et al., 1986; PALLANT e RIHA, 1990; AMIOTTI et al., 2000).

Os resultados dos valores de $\mathrm{pH}$ podem ser decorrentes da lavagem de elementos minerais e compostos orgânicos provenientes das folhas da copa e do tronco pela água da chuva, ocasionando a acidificação do solo. Nesse sentido, Lima (1979), ao conduzir estudo por 15 meses em Piracicaba, SP, verificou que as amostras de água da chuva apresentavam $\mathrm{pH}$ médio de 5,2 e as amostras de água coletadas sob floresta de Pinus caribaea (precipitação interna), $\mathrm{pH}$ médio de 4,5. Segundo esse autor, a alteração da composição química da água da chuva pode ser decorrente do fato de as copas da floresta atuarem como superfícies depositárias de partículas secas durante períodos sem chuvas, as quais são, então, carreadas para o solo pelas águas das chuvas. Além disso, Ryan e McGarity (1983), ao realizarem estudos na Austrália, observaram que a presença de ácidos orgânicos na água da chuva que escoava pelo tronco do Eucalyptus grandis era o principal agente causador de maior acidez no solo mais próximo do tronco da árvore do que a maiores distâncias ( $100 \mathrm{~cm}$ do eucalipto).

O acréscimo nos valores de $\mathrm{pH}$ com a distância do tronco do eucalipto aos 54 meses, na camada de 20-40 cm, na entrelinha (Figura 2), pode ser atribuído ao fato de essa camada apresentar maior teor de argila em relação às camadas superiores (Tabela 1), o que, de certa forma, pode ter oferecido maior resistência à percolação da água da chuva, ressaltando-se que isso não deve ter ocorrido nas camadas superiores do solo, devido ao maior teor de areia grossa. Além disso, Sousa et al. (2007) argumentaram que os maiores teores de argila nos solos relacionam-se diretamente com o poder-tampão hidrogeniônico do solo, o que contribuiu para maior resistência na alteração do $\mathrm{pH}$ na camada de $20-40 \mathrm{~cm}$ sob esse povoamento.

Os menores valores de $\mathrm{pH}$ mais próximo do tronco do eucalipto do que a maiores distâncias provavelmente favoreceram a solubilização do $\mathrm{Al}^{3+}$. Consequentemente, os teores desse elemento foram significativamente maiores nessa posição sob os povoamentos aos 31 e 84 meses do que a maiores distâncias na direção da linha de plantio e da entrelinha, nas três camadas de solos amostradas (Figuras 1 e 3). Ryan e McGarity (1983) também verificaram a ocorrência de maiores teores de $\mathrm{Al}^{3+}$ no solo mais próximo do tronco de Eucalyptus grandis do que a maiores distâncias. Contudo, sob o povoamento de eucalipto aos 54 meses verificou-se que nas camadas de $0-10$ e $10-20 \mathrm{~cm}$, os teores de $\mathrm{Al}^{3+}$ corresponderam à metade daqueles registrados nestas camadas sob os povoamentos de eucalipto aos 31 e 84 meses, fato que pode ser atribuído aos maiores valores de $\mathrm{pH}$ mais próximo do tronco do eucalipto aos 54 meses, nestas camadas, do que a maiores distâncias (Figura 2). De acordo com Salgado et al. (2006), valores de $\mathrm{pH}$ mais próximo da neutralidade podem reduzir a solubilidade do $\mathrm{Al}^{3+}$

Os maiores teores de $\mathrm{Mg}^{2+}$ verificados na maior distância do tronco do eucalipto aos 31 meses podem ser atribuídos à aplicação de cinza de biomassa florestal sob esse povoamento. Segundo Gonçalves e Moro (1995), a aplicação desse insumo ao solo eleva os teores de $\mathrm{Mg}^{2+}$, os quais podem ser mais facilmente detectados quando as avaliações da fertilidade do solo são realizadas em intervalo de tempo mais curto entre a época de aplicação e a análise das amostras de solo.

Os decréscimos nos teores de $\mathrm{P}, \mathrm{Ke} \mathrm{Ca}^{2+}$ à medida que se afastou do tronco do eucalipto aos 31, 54 e 84 meses na direção da linha de plantio e da entrelinha, nas três camadas de solo amostradas e de $\mathrm{Mg}^{2+}$, à exceção do povoamento aos 31 meses, podem ser explicados pela distribuição espacial heterogênea do sistema radicular do eucalipto. Nesse sentido, Bouillet et al. (2002), ao estudarem a distribuição espacial de raízes de clones de eucalipto com a idade, no Congo, observaram que na posição de amostragem sob o tronco e a 75 e $150 \mathrm{~cm}$ de distância deste, na direção da linha de plantio e da entrelinha, a densidade de raízes finas $(0,1$ a $1,0 \mathrm{~mm})$ foi, respectivamente, de 32,19 e $16 \%$ em relação ao total de raízes obtidas na camada de 0-25 cm de profundidade sob o clone de eucalipto aos 
12 meses de idade. Esse mesmo clone, avaliado aos 24 e 108 meses de idade nas três posições de amostragem e na direção da linha e entrelinha apresentou densidade de raízes finas de 32, 32 e 36\% e 42, 45 e 53\%, respectivamente. Esses resultados evidenciam que ocorre aumento na densidade de raízes finas a maiores distâncias do tronco do eucalipto com o decorrer da idade. Nesse sentido, Bouillet et al. (2002) verificaram que as raízes de clones de eucalipto cresciam, em média, $0,8 \mathrm{~cm} \mathrm{dia}^{-1}$, e Gatto et al. (2003) observaram que as raízes de Eucalyptus grandis aos 38 meses de idade alcançaram o comprimento de 488,0 $\mathrm{cm} \mathrm{g}^{-1}$, em média, de raiz seca. De acordo com Barber (1995), a produção de raízes longas e finas são características desejáveis para aumentar a eficiência de absorção de nutrientes de baixa mobilidade no solo, como o P, bem como dos demais nutrientes do solo (FAHEY e HUGHES, 1994).

Com base na distribuição do sistema radicular do eucalipto, pode-se aventar sobre a possibilidade de o mesmo ter contribuído para absorção mais eficiente dos nutrientes localizados a maiores distâncias do tronco do eucalipto, nas idades avaliadas, como também da possibilidade de nas posições mais afastadas do tronco do eucalipto ter havido maior competição pelos nutrientes do solo pelas demais árvores de eucalipto presentes no povoamento florestal, promovendo, dessa forma, diminuição nos teores dos nutrientes.

Pode, ainda, ter contribuído para os decréscimos nos teores de nutrientes, à medida que se afastou do tronco do eucalipto na direção da linha de plantio e da entrelinha, a aplicação de $100 \mathrm{~g}$ da formulação NPK 06-30-06 por cova de plantio do eucalipto aos $31 \mathrm{e}$ 54 meses e de $56 \mathrm{~g}$ de superfosfato triplo por cova de plantio do eucalipto aos 84 meses. Além disso, Laclau et al. (2000) argumentaram que a entrada de nutrientes via percolação pelo tronco do eucalipto também deve ser considerada como fonte adicional de nutrientes ao solo e que, portanto, pode ter contribuído para os resultados deste trabalho.

Foram quantificados os teores de $\mathrm{P}$ do solo em contato com o tronco do eucalipto aos 84 meses de idade e aqueles obtidos à distância de 30 e 150 cm do tronco na camada de $0-20 \mathrm{~cm}$ de profundidade (soma dos teores da camada de 0-10 e 10-20 cm). Dessa forma, os seguintes teores de $\mathrm{P}$ foram encontrados: 31,65 ; 9,61; e 5,13 $\mathrm{mg} \mathrm{dm}^{-3}$ e 31,35; 11,75; e 8,00 $\mathrm{mg} \mathrm{dm}^{-3} \mathrm{na}$ direção da linha de plantio e da entrelinha, respectivamente (Figura 3). Ou seja, os teores de $\mathrm{P}$ do solo a $30 \mathrm{~cm}$ do tronco do eucalipto foram $53,4 \%$ e $68,1 \%$ superiores àqueles localizados a $150 \mathrm{~cm}$ desse tronco, na direção da linha de plantio e da entrelinha, respectivamente. Os teores de $\mathrm{P}$ obtidos foram inferiores no nível crítico de implantação $\left(70 \mathrm{mg} \mathrm{dm}^{-3} \mathrm{em}\right.$ solo de textura média), mas superiores ao de manutenção para incremento médio anual de $50 \mathrm{~m}^{3} \mathrm{ha}^{-1}$ ano $^{-1}(6,5$ $\mathrm{mg} \mathrm{dm}^{-3}$ ), conforme CFSEMG (1999). Adotando-se o mesmo procedimento para o potássio, foram obtidos: 80,56 e $43 \mathrm{mg} \mathrm{dm}^{-3}$ e 79, 60 e $45 \mathrm{mg} \mathrm{dm}^{-3}$ na direção da linha de plantio e da entrelinha, respectivamente, nas posições de amostragem ao redor do tronco do eucalipto aos 84 meses e nas distâncias de 30 e 150 $\mathrm{cm}$ desse tronco (Figura 3). Dessa forma, tem-se que os teores de $\mathrm{K}$ localizados a $30 \mathrm{~cm}$ do tronco do eucalipto foram $76,8 \%$ e 75,0\% superiores àqueles localizados a $150 \mathrm{~cm}$ na direção da linha de plantio e da entrelinha, respectivamente. Os teores de $\mathrm{K}$ quantificados a 30 $\mathrm{cm}$ do tronco do eucalipto na direção da linha de plantio e da entrelinha estão acima do nível crítico de implantação para o eucalipto $\left(10 \mathrm{mg} \mathrm{dm}^{-3}\right)$ e próximos daqueles para o nível crítico de manutenção para incremento médio anual de $30 \mathrm{~m}^{3} \mathrm{ha}^{-1} \mathrm{ano}^{-1}\left(60 \mathrm{mg} \mathrm{dm}^{-3}\right)$, segundo CFSEMG (1999).

Com base nos teores de $\mathrm{P}$ e de $\mathrm{K}$ do solo quantificados nas posições de coleta das amostras de solo mais próximas do tronco do eucalipto aos 84 meses de idade, em relação às posições mais afastadas, pode-se aventar, portanto, sobre a possibilidade de, após o corte florestal, ser realizado o plantio das mudas de eucalipto mais próximo da cepa remanescente do eucalipto. Isso porque há maior disponibilidade de nutrientes para as mudas, as quais poderão se beneficiar dos maiores teores de $\mathrm{P}$ e $\mathrm{K}$ presentes no solo em contato com a cepa remanescente do eucalipto. Soma-se a isso, ainda, o fato de, no decorrer do processo de decomposição e mineralização da cepa remanescente, haver possivelmente liberação de nutrientes para o solo, os quais são passíveis de serem absorvidos pelo eucalipto da reforma do povoamento.

Os valores de $\mathrm{pH}$ e os teores de $\mathrm{P}, \mathrm{K}, \mathrm{Ca}^{2+}, \mathrm{Mg}^{2+}$

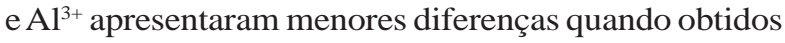
na direção da linha de plantio ou na entrelinha do povoamento de eucalipto aos 84 meses, à exceção do $\mathrm{Ca}^{2+}$, na camada de $0-10 \mathrm{~cm}$, e, ainda, apresentaram as mesmas tendência de aumento ou decréscimo nos seus valores com o distanciamento do tronco do eucalipto

R. Árvore, Viçosa-MG, v.33, n.5, p.799-810, 2009 
nessa idade, em comparação com aqueles determinados sob o povoamento de eucalipto aos 31 e 54 meses, nas três profundidades avaliadas (Figuras 1, 2 e 3 ). Tal fato pode ser atribuído à menor interferência antrópica associadas às práticas silviculturais realizada sob o povoamento de eucalipto aos 84 meses. Nesse sentido, cabe ressaltar que no povoamento avaliado aos 84 meses se fez apenas a abertura de covas manualmente, às quais foram adicionados $56 \mathrm{~g}$ de superfosfato triplo por mudas de eucalipto. No entanto, nos povoamentos avaliados aos 31 e 54 meses foram realizadas as seguintes práticas silviculturais: subsolagem, aplicação de fosfato natural, aplicação de fertilizante no plantio e em cobertura e, ainda, aplicação de cinza de biomassa florestal em duas épocas, o que muito provavelmente contribuiu para os acréscimos e decréscimos nas características químicas do solo determinadas a diferentes distâncias do tronco do eucalipto aos 31 e 54 meses na direção da linha e, ou, da entrelinha, nas três camadas de solo amostradas.

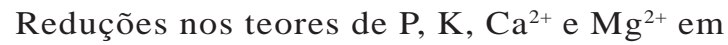
profundidade têm sido observadas em plantios de eucalipto (GATO et al., 2003; CAVICHIOLLO et al., 2004). Os maiores teores de nutrientes na camada superficial do solo podem ser decorrentes da aplicação de fertilizantes e cinza de biomassa florestal, em área total, a lanço e, ainda, da permanência dos restos culturais provenientes da colheita da floresta sobre a superfície do solo. Além disso, os teores mais elevados de $\mathrm{P}$ verificados sob os povoamentos de eucalipto aos 31 e 54 meses podem ser atribuídos à utilização de extratores ácidos como o Mehlich-1, o qual promove a solubilização das partículas do fosfato natural reativo aplicado na época de plantio desses povoamentos, proporcionando valores superestimados do P disponível (NOVAIS e SMYTH, 1999).

Os maiores teores de $\mathrm{Ca}^{2+}$ verificados na profundidade de $20-40 \mathrm{~cm}$, sob o povoamento de eucalipto aos 54 meses (Figura 2), podem ser decorrentes da lixiviação desse elemento, uma vez que, a CTC efetiva do solo em contato com o tronco do eucalipto na direção da linha de plantio e da entrelinha foi de $1,81 \mathrm{cmol}_{\mathrm{c}}$ $\mathrm{dm}^{-3}$ e $1,73 \mathrm{cmol}_{\mathrm{c}} \mathrm{dm}^{-3}$, respectivamente. Esses valores são classificados como "baixo" (0,81 a 2,30 $\left.\mathrm{cmol}_{\mathrm{c}} \mathbf{d m}^{-3}\right)$, conforme CFSEMG (1999).

R. Árvore, Viçosa-MG, v.33, n.5, p.799-810, 2009
Menores teores de $\mathrm{Al}^{3+}$ na camada superficial do solo também foram verificados por Leite (2001), segundo o qual o aumento dos teores de $\mathrm{Al}^{3+}$ em profundidade pode ser consequência da redução dos teores de bases no perfil do solo, como também do $\mathrm{pH}$. Além disso, a formação de complexos insolúveis entre a matéria orgânica e o $\mathrm{Al}^{3+}$ provoca seu aumento em profundidade (CANELLAS et al., 2000), devido ao favorecimento da lixiviação desse complexo, sobretudo, em solos com maiores teores de areia grossa nas camadas superficiais (Tabela 1).

Os teores de $\mathrm{K}$ foram maiores no povoamento com 31 meses, em razão, provavelmente, da proximidade da época de aplicação das adubações de plantio e de manutenção das formulações NPK 10-00-30 e 20-05-20, somados à cinza de caldeira de biomassa florestal aplicada em área total (10 a 14 meses pós-plantio).

Maiores teores de $\mathrm{Ca}^{2+}$ e de $\mathrm{Mg}^{2+}$ verificados no povoamento com 84 meses podem ser decorrentes, possivelmente, da decomposição dos resíduos florestais (folhas, galhos, frutos, cascas etc.). Isso porque, nesse povoamento, não se fez a aplicação de fertilizantes ou corretivos cuja fonte contivesse $\mathrm{Ca}^{2+}$ e $\mathrm{Mg}^{2+}$ na sua composição na rotação atual, além do fato de esses elementos serem exigidos em menores quantidades pelo eucalipto nessa idade (CAVICHIOLLO et al., 2004).

\section{CONCLUSÕES}

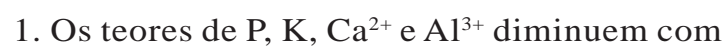
a distância do tronco do eucalipto aos 31, 54 e 84 meses, e os valores de $\mathrm{pH}$ aumentam à medida que se afasta do tronco do eucalipto aos 31 e 84 meses, assim como os teores de $\mathrm{Mg}^{2+}$ em relação ao tronco do eucalipto aos 31 meses, na direção da linha e entrelinha, nas três profundidades de amostragem.

2. Os valores de $\mathrm{pH}, \mathrm{P}, \mathrm{K}, \mathrm{Ca}^{2+}, \mathrm{Mg}^{2+} \mathrm{e} \mathrm{Al}^{3+}$ são diferentes quando obtidos na direção da linha de plantio e na entrelinha dos povoamentos de eucalipto nas três idades e profundidades avaliadas. Mas TENDEM A SER mais semelhantes quando obtidos na linha e entrelinha do povoamento de eucalipto aos 84 meses, exceto $\mathrm{Ca}^{2+}$ na camada de $0-10 \mathrm{~cm}$ de profundidade.

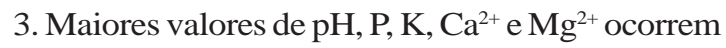
na camada de $0-10 \mathrm{~cm}$ e de $\mathrm{Al}^{3+}$ nas camadas subsuperficiais.

\section{R. Árvore, Viçosa-MG, v.33, n.5, p.799-810, 2009}




\section{REFERÊNCIAS}

AMIOTTI, N. M. et al. The impact of single trees on properties of loess-derived grassland soils in Argentina. Ecology, v.81, n.12, p.3283-3290, 2000 .

BARBER, S. A. Soil nutrient

bioavailability: a mechanistic approach. New York: John Wiley, 1995. 414p.

BOUILLET, J. P. et al. Changes with age in the spatial distribution of roots of Eucalyptus clone in Congo. Impact on water and nutrient uptake. Forest Ecology and Management, v.171, n. 1, p.43-57, 2002.

CAMBARDELLA, C. A. et al. Field scale variability of soil properties in Central Iowa soils. Soil Science Society American Journal, v.58, p.1501-1511, 1994.

CANELLAS, L. P. et al. Frações da matéria orgânica em seis solos de uma toposseqüência no estado do Rio de Janeiro. Pesquisa

Agropecuária Brasileira, v.35, n.5, p.133$143,2000$.

CAVICHIOLLO, S. R.; DEDECEK, R. A.; GAVA, J. L. Preparo do solo e o estado nutricional da rebrota de Eucalyptus saligna. Scientia Forestalis, n.66, p.120-127, 2004.

\section{COMISSÃO DE FERTILIDADE DO SOLO DO} ESTADO DE MINAS GERAIS - CFSEMG. Recomendações para uso de corretivos e fertilizantes em Minas Gerais: $5^{\circ}$ aproximação. Viçosa, MG: 1999. 359p.

EMPRESA BRASILEIRA DE PESQUISA AGROPECUÁRIA - EMBRAPA. Serviço Nacional de Levantamento e Conservação de Solos. Manual de métodos de análises de solo. 2.ed. Rio de Janeiro, 1997. 212p.

EMPRESA BRASILEIRA DE PESQUISA AGROPECUÁRIA - EMBRAPA. Serviço Nacional de Levantamento e Conservação de Solos. Sistema brasileiro de classificação de solos. Rio de Janeiro, 1999. 412p.

FAHEY, T. J.; HUGHES, J. W. Fine root dynamics in a northern hardwood forest ecosystem. Hubbard Book Experimental Forest, NH. Journal of Ecology, v.82, p.533-548, 1994.
GATTO, A. et al. Efeito do método de preparo do solo, em área de reforma, nas suas características, na composição mineral e na produtividade de plantações de Eucalyptus grandis. Revista Árvore, v.27, n.5, p.635-646, 2003.

GONÇALVES, J. L. M.; MORO, L. Uso da "cinza" de biomassa florestal como fonte de nutrientes em povoamentos puros de Eucalyptus grandis. IPEF, v.48/49, p.28-37, 1995.

LACLAU, J. P.; BOUILLET, J. P.; RANGER, J. Canopy and soil modification of precipitation chemistry in a clonal eucalypt stand in Congo. Comparison with an adjacent savanna ecosystem. In: IUFRO WORD CONGRESS, 21., 2000, Kuala Lumpur. Proceedings... Kuala Lumpur, Malaysia, 2000. v.1.p.706-718.

LEITE, F. P. Relações nutricionais e alterações de características químicas de solos da região do Vale do Rio Doce pelo cultivo do eucalipto. 2001. 72f. Tese (Doutorado em Solos e Nutrição de Plantas)Universidade Federal de Viçosa, Viçosa, MG, 2001.

LIMA, W. P. Alteração do pH, condutividade e das concentrações de $\mathrm{Ca}, \mathrm{Mg}$ e $\mathrm{P}$ da água da chuva em floresta de Pinus caribaea Morelet var. caribaea. IPEF, n.18, p.37-54, 1979.

MAlavolta, E. ABC da análise de solos e folhas. São Paulo: Ceres, 1992. 124p.

MIRANDA, G. A. et al. Produção de povoamentos de eucalipto em regime de talhadia, em função da adubação e da distribuição da galhada da rotação anterior, no Vale do Jequitinhonha-MG. Revista Árvore, v.22, n.2, p.307-314, 1998.

NOVAIS, R. F.; SMYTH, T. J. Fósforo em solo e planta em condições tropicais. Viçosa, MG: Universidade Federal de Viçosa, 1999. 399p.

PALLANT, E.; RIHA, S. J. Surface soil acidification under red pine e norway spruce.

Soil Science Society American Journal, v.54, p.1124-1130, 1990.

PRADO, R. M.; FERNANDES, F. M.; ROQUE, C. G. Amostragem do solo em área com cana-de-açúcar após aplicação de corretivos. Pesquisa Agropecuária Brasileira, v.36, n.9, p.1185-1190, 2001.

R. Árvore, Viçosa-MG, v.33, n.5, p.799-810, 2009 
RAIJ, B. van. et al. (Ed). Recomendações de adubação e calagem para o Estado de São Paulo. 2.ed. Campinas: Instituto Agronômico de Campinas, 1996. 39p. (Boletim Técnico, 100).

RIHA, S.J. et al. Spatial variability of soil $\mathrm{pH}$ and organic matter in forest plantations. Soil

Science Society American Journal, v.50, p.1347-1352, 1986.

RYAN, P. J.; McGARITY, J. W. The nature and spatial variability of soil properties adjacent to large forest eucalypts. Soil Science Society American Journal, v.47, p.286-293, 1983.

SALGADO, B. G. et al. Avaliação da fertilidade dos solos de sistemas agroflorestais com cafeeiro (Coffea arabica L.) em Lavras-MG. Revista Árvore, v.30, n.3, p.343-349, 2006.
SCHLINDWEIN, J. A.; ANGHINONI, I. Variabilidade vertical de fósforo e potássio disponíveis e profundidade de amostragem do solo no sistema plantio direto. Ciência Rural, v.30, n.4, p.611-617, 2000.

SILVA, V. R. et al. Variabilidade espacial das características químicas do solo e produtividade de milho em um argissolo vermelho-amarelo distrófico arênico. Revista Brasileira de Ciência do Solo, v.27, n.6, p.1013-1020, 2003.

SOUSA, D. M. G.; MIRANDA, L. N.; OLIVEIRA, S. A. Acidez do solo e sua correção. In: NOVAIS, R. F. et al. Fertilidade do solo. Viçosa, MG: Sociedade Brasileira de Ciência do Solo, 2007. p.205-274.

SOUZA, L. S.; COGO, N. P.; VIERA, S. R. Variabilidade de fósforo, potássio e matéria orgânica no solo, em relação a sistemas de manejo. Revista Brasileira de Ciência do Solo, v.22, n.1, p.77-86, 1998. 